Revista Tecné, Episteme y Didaxis: TED. Año 2014, Número Extraordinario. ISSN Impreso: 0121-3814, ISSN web: 2323-0126

Memorias, Sexto Congreso Internacional sobre Formación de Profesores de Ciencias. 08 al 10 de octubre de 2014, Bogotá

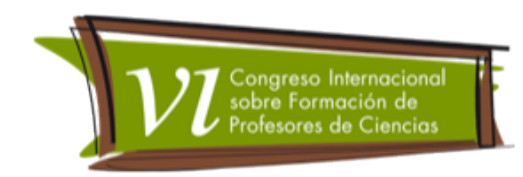

\title{
A colher que desaparece como dispositivo de aprendizagem em Química Escolar
}

Telles, Jardel' E Loguercio, Rochele de Quadros ${ }^{2}$

Categoria 2. Trabalho de investigação

\section{Resumo}

Este trabalho é parte de uma pesquisa sobre as contribuições da literatura de divulgação científica como recurso didático no ensino de química, no ensino médio. Compõe-se como um recorte em que se utiliza um dos títulos de literatura, qual seja, - A colher que desaparece: E outras histórias reais de loucura, amor e morte a partir dos elementos químicos - em duas turmas de primeiro ano do ensino médio regular de uma escola pública de Porto Alegre. Com base nesta abordagem literária, pôde-se evidenciar que as dinâmicas de leitura ajudam na interação aluno-professor, e uma melhor compreensão dos conceitos tradicionais através da história da ciência.

\section{Palavras-chave}

Literatura de divulgação científica; incentivo à leitura; cultura científica.

\section{Objetivo}

Esta pesquisa evidencia uma proposta didática em que se investigou a potência da Literatura de Divulgação Científica na construção de um conhecimento químico sobre reações inorgânicas, bem como analisa a possibilidade de ampliar a capacidade de leitura dos alunos da escola básica.

Assim, de posse de algumas ferramentas teóricas, empreendemos uma ação pedagógica na escola utilizando como dispositivo literário o livro A colher que desaparece para ensinar conceitos químicos, relacionando estes conceitos com os contextos históricos e aspectos sociais atuais.

' UFRGS. jardelrock87@gmail.com

2 UFRGS. rochele_loguercio@yahoo.com.br 
Revista Tecné, Episteme y Didaxis: TED. Año 2014, Número Extraordinario. ISSN Impreso: 0121-3814, ISSN web: 2323-0126

Memorias, Sexto Congreso Internacional sobre Formación de Profesores de Ciencias. 08 al 10 de octubre de 2014, Bogotá

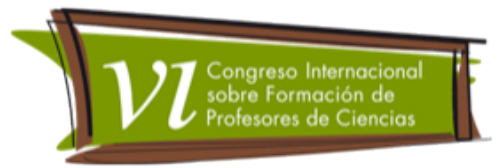

\section{Referencial teórico}

A literatura e seus elementos culturais e narrativos, acessados para compor esse trabalho de investigação, se relacionam diretamente com a história da Química e, por esta razão, é importante identificar que entendemos que essa literatura, que se quer histórica, é diferente da história tradicional. No entanto, como dispositivo literário, ela se aproxima da história de Foucault e baseia a tríade (História, Cultura e Literatura) que norteia esta pesquisa e sua importância no processo de ensino aprendizagem. A história é entendida por Michel Foucault como:

A proveniência fornece as relações que estão em jogo, não através de um passado sempre reconduzido, mas na instância em que ocorrem as disputas, as lutas que permitem que determinado saber se sobreponha aos outros. (Foucault, 1979, pág. 22)

A ficção e a história são narrativas próximas que se distinguem apenas por suas estruturas. Essa interação pressupõe a dúvida com relação à autenticidade e a inautenticidade dos objetos a serem analisados. Por isso, reescrever o passado na ficção constitui o mesmo processo da escrita da história, ambos os casos revelam o fato ao presente. Para Hutcheon, isso impede que, tanto a história como a literatura, sejam conclusivas e teleológicas, ou seja, a relação da escrita com o fato sempre é questionável. (Jacomel; Silva, 2009)

O papel da LDC - Literatura de Divulgação Científica - vem contribuir na compreensão dos conceitos científicos que não são alcançados pelas abordagens tradicionais encontradas nos livros didáticos, com seus obstáculos epistemológicos e repetição dos conteúdos de maneira quase industrial. A narrativa encontrada na LDC instiga a curiosidade e a pesquisa dos assuntos tratados outrora de maneira maçante e repetitiva e "a introdução de aspectos da História da Ciência possibilita que os alunos compreendam melhor como a ciência é construída e que repercussões sociais têm estes conhecimentos" (Strack et al., 2005). O uso da LDC na sala de aula é uma alternativa ao modelo onde a transmissão do saber acadêmico dá-se de forma verticalizada, não levando em conta os saberes construídos no cotidiano, como bem disse Strack et al. (2005). A possibilidade de se trabalhar a cultura científica, em sala de aula, embasada na literatura de divulgação, traz uma boa perspectiva de aprendizagem.

Por fim, esta aprendizagem deve levar em consideração os conhecimentos 
Revista Tecné, Episteme y Didaxis: TED. Año 2014, Número Extraordinario. ISSN Impreso: 0121-3814, ISSN web: 2323-0126

Memorias, Sexto Congreso Internacional sobre Formación de Profesores de Ciencias. 08 al 10 de octubre de 2014, Bogotá

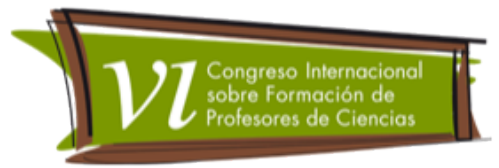

prévios do estudante numa referência dita por Loguercio (1999) à aprendizagem significativa. Aprendizagem esta que evidencia os pontos de contato entre 0 saber científico e o saber cotidiano, originando um currículo onde se valoriza um saber escolar que é único no contexto em que está inserido (Loguercio, 1999).

\section{Metodologia}

Os trabalhos de Strack et al. produziram um certo número de análises sobre os livros de LDC na perspectiva de sua validade como conhecimento químico próprio aos conhecimentos científicos legítimos. Estes trabalhos datam de 2005 e não analisam o livro A Colher que Desaparece (Kean, 2011), utilizado como referência nesse estudo.

Uma breve análise do livro abordado demonstra que ele se caracteriza por ser histórico e rico em detalhes, trazendo muitas curiosidades das atividades científicas mais importantes do mundo, o que prende o leitor e pode ser uma atração para os alunos. Juntamente às curiosidades, o autor emite também muitas opiniões e nem sempre deixa claro a diferença entre elas e a informação histórica. Nesse sentido, é adequada a preocupação em relativizar e aprimorar a informação. Podemos perceber também piadas e gracejos como estratégia literária visando o interesse do interlocutor que não devem passar despercebidas para uma análise mais atenta. As estratégias de utilização dos títulos de LDC, portanto, dependem tanto de uma análise crítica do livro e de um estudo das condições encontradas ao chegar na instituição de ensino.

Em nossa pesquisa definiu-se, já nos primeiros dias de contato com a instituição, que estariam disponíveis duas turmas de primeiro ano do ensino médio, e que o conteúdo a ser ministrado nas aulas deveria passar, impreterivelmente, pelas definições e exemplos das Reações Inorgânicas.

A abordagem literária se deu através de trechos escolhidos do livro que serviriam como mobilizadores do interesse e do conhecimento químico de Reações Inorgânicas. Demostramos a seguir dois excertos para melhor explicitar nossa pesquisa:

O primeiro é o trecho do livro; o segundo é o registro de nossas observações sob a forma de Diário de Campo.

"Um dos elementos que está sempre pronto a formar bolhas é o 
Revista Tecné, Episteme y Didaxis: TED. Año 2014, Número Extraordinario. ISSN Impreso: 0121-3814, ISSN web: 2323-0126

Memorias, Sexto Congreso Internacional sobre Formación de Profesores de Ciencias. 08 al 10 de octubre de 2014, Bogotá

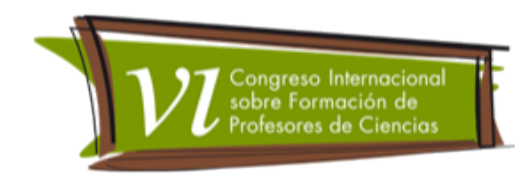

cálcio.

(...)

Há milênios escultores vêm moldando túmulos, obeliscos e falsos deuses em rochas de cálcio, ao mesmo tempo duras e complacentes, como o mármore e o calcário. Essas rochas se formam quando minúsculas criaturas marinhas morrem e suas conchas ricas em cálcio afundam e se empilham no leito oceânico. Assim como os ossos, essas conchas têm poros naturais, mas a composição do cálcio aumenta sua resistência. Quase toda a água natural, como a água da chuva, é levemente ácida, mas os minerais de cálcio são levemente básicos. Quando a água penetra os poros do cálcio, as duas substâncias reagem como um pequeno vulcão liberando pequenas quantidades de dióxido de carbono, que amolecem a rocha. Numa escala maior, geológica, essas reações entre a água da chuva e o cálcio formam as grandes cavidades que conhecemos como cavernas.

A Nasa usa espumas especiais para proteger os ônibus espaciais na reentrada na atmosfera." (KEAN, 2011, pág. 282-283)

"O texto trabalhado era um recorte de um dos capítulos. Recorte elaborado com as partes que julguei necessárias e que faziam sentido serem lidas uma após a outra, sem, necessariamente, terem esta ordem. Sobre abordagens diferentes, já havia notado uma maior tranquilidade nas aulas quando estas eram realizadas fora da sala de aula habitual e optei, pela sala de vídeo onde esperava que fosse mais tranquila a leitura.

De fato ajudou, mas não como o esperado. As resistências surgiram e as exigências precisavam, progressivamente, acompanhá-las. Os temas pareciam que não eram tão interessantes (talvez pelo fato de que soubessem que posteriormente haveria uma cobrança do conteúdo e que a leitura era parte fundamental para isso), e a atenção se dispersava facilmente. Foi então que como medida de inovação pedi aos alunos que anotassem todas as palavras curiosas que eles encontrassem, assim como assinalassem os trechos de maior interesse, seja por dificuldade ou curiosidade. Após a leitura, e a insistência veemente de que eles fizessem as tarefas propostas, pude iniciar o debate através dessas anotações, perguntando qual 
Revista Tecné, Episteme y Didaxis: TED. Año 2014, Número Extraordinario. ISSN Impreso: 0121-3814, ISSN web: 2323-0126

Memorias, Sexto Congreso Internacional sobre Formación de Profesores de Ciencias. 08 al 10 de octubre de 2014, Bogotá

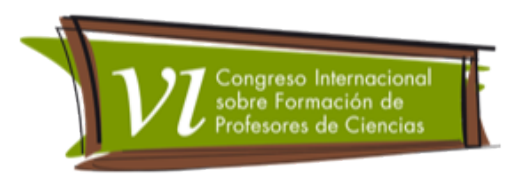

as palavras e trechos eles deram destaque. Com isso, a aula seguiu surpreendentemente bem e tivemos êxito com a conclusão da matéria e as abordagens relacionando o conteúdo ao texto trabalhado." (Diário de campo, outubro de 2013)

Este trecho foi escolhido por se tratar de uma reação química simples e que envolvia diversas curiosidades e aplicações no cotidiano. Com compostos somente inorgânicos, era possível recriar a reação presente no texto e explicar todos os aspectos da mesma. Além de ser possível trabalhar esse tipo de reação com visualização no âmbito micro (das conchas) e macro (com a formação das cavernas). Sobretudo, ainda, havia curiosidades que poderiam manifestar os interesse dos estudantes, desde a estrutura dos ossos, passando pela formação do mármore e do calcário e nas supertecnológicas estruturas das naves espaciais.

Este trecho, marca um amadurecimento pessoal da aplicação de aprendizagens da educação em ciências, com a valorização das perspectivas da psicologia e da sociologia da ciência. Cada detalhe da aula precisou ser planejado levando em consideração as aprendizagens próprias da educação em ciências: abordagens do macro para o micro, respeitando o desenvolvimento cognitivo dos alunos, como nos indicam os pesquisadores da educação química Del Pino e Loguercio (2007); aprendizagens próprias da sociologia da educação, em que se marca uma diversidade de temas buscando interpelar um número maior de estudantes.

\section{Resultados}

A leitura era a parte principal do aprendizado agora e era preciso lidar com a ansiedade e excitação ao novo, assim como também, respeitar o instante para que se aproveitasse plenamente o que se lia, e usar isso em benefício dos alunos na compreensão dos conceitos a serem trabalhados. E a concentração necessária é inimiga da empolgação expressada. Era sempre imprescindível muitas explicações e exigências para que houvesse o foco relevante à atividade, talvez pela falta de práticas consistentes de incentivo à leitura no ensino médio, talvez por inabilidade do educador, mas a dificuldade estava ali presente e precisava ser trabalhada.

Ressaltou-se as informações relevantes presentes na LDC, e o entendimento de que os conteúdos não estão presentes somente em livros didáticos, eles estão diariamente sendo trabalhados nos mais diversos setores da sociedade e não só 
Revista Tecné, Episteme y Didaxis: TED. Año 2014, Número Extraordinario. ISSN Impreso: 0121-3814, ISSN web: 2323-0126

Memorias, Sexto Congreso Internacional sobre Formación de Profesores de Ciencias. 08 al 10 de octubre de 2014, Bogotá

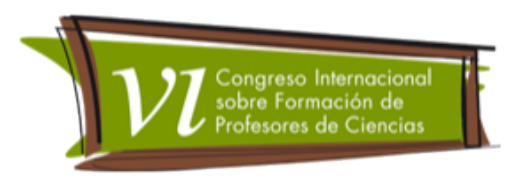

podem como devem chegar aos estudantes de outras maneiras.

\section{Conclusões}

Reiteradamente se discute a dificuldade de entendimento dos alunos com relação à leitura dos enunciados das questões científicas. Da mesma forma, se critica a incapacidade de compreender o que leem, sem, no entanto, se construir uma cultura de leitura na escola. As dificuldades de leitura são reais e atuais. Nesse sentido, as negociações na sala de aula investigada se fizeram necessárias e constantes.

No entanto, toda a proposta curricular tem que estar apoiada na cultura de procedência do alunado (Torres Santomé, 1997, pág. 13) e a literatura se mostrou de grande relevância e com potencialidade para despertar a curiosidade e a motivação dos estudantes, particularmente por sua narrativa romanceada. Além do óbvio incentivo à leitura e interpretação de textos, a LDC desperta um interesse histórico dos conceitos químicos e da origem dos mesmos. Notou-se, durante toda a aplicação e desenvolvimento do trabalho, que a literatura tem influência sobre o aprendizado de tal forma que o seu uso em sala de aula desperta o interesse em conteúdos que não atraem a atenção por serem tratados descontextualizadamente ao longo dos anos.

Enfim, a tríade História, Cultura e Literatura como estratégia didática se mostrou potente, pois os trechos literários permitem uma discussão mais ampla que evidencia a cultura do aluno e seu acesso a outras formas culturais, bem como promove as ligações necessárias com o conhecimento químico tornando-o contextual e. portanto, significativo. A promoção da leitura é um ganho óbvio para todas as disciplinas $e$ as dificuldades iniciais foram transpostas e aproveitadas para enriquecer a troca de ensinamentos e esta via de mão dupla se dá mais em um sentido do que em outro, onde aquele que sai mais profundamente enobrecido do que entrou é o professor.

\section{Referências bibliográficas}

Foucault, Michel. Nietzsche, (1979) A Genealogia E A História. In: Microfísica Do Poder. Organização E Tradução De Roberto Machado. Rio De Janeiro: Edições Graal..

Jacomel, Mirele Carolina Werneque; Silva, Marisa Correa. (2009) Discurso Histórico E Discurso Literário: $\mathrm{O}$ Entrelace $\mathrm{Na}$ Perspectiva Da Metaficção 
Revista Tecné, Episteme y Didaxis: TED. Año 2014, Número

Extraordinario. ISSN Impreso: 0121-3814, ISSN web: 2323-0126

Memorias, Sexto Congreso Internacional sobre Formación de Profesores de Ciencias. 08 al 10 de octubre de 2014, Bogotá

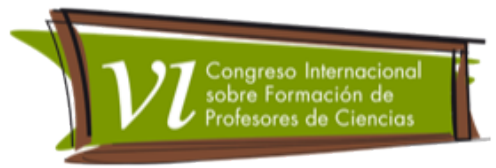

Historiográfica. In: Celli - Colóquio De Estudos Lingüísticos E Literários. 3, 2007. Maringá. Anais... Maringá, Pr, pág. 740-748.

Kean, Sam. (2011) A Colher Que Desaparece: E Outras Histórias Reais De Loucura, Amor E Morte A Partir Dos Elementos Químicos. Rio De Janeiro: Zahar.

Loguercio, R. (1999) Conhecimentos Implícitos E Interesse Dos Alunos $\mathrm{Na}$ Construção De Um Currículo De 8a Série. Dissertação De Mestrado, PpbioqUfrgs.

Loguercio, R. De Q.; Del Pino, J. C. (2007) Em Defesa Do Filosofar E Do Historicizar Conceitos Científicos. Revista História Da Educação, N.23, pág.67-96.

Strack, R.; Loguercio, R.; Del Pino, J. C. (2005) Literatura Científica E Perfil Conceitual Químico Dos Alunos. Anais Do V Enpec, N.5.

Torres Santomé, J. (1997) Globalización Y Interdisciplinariedad: El Curriculum Integrado. Madrid: Morata. 